\title{
Clinical relevance of plasma miR-106b levels in patients with chronic obstructive pulmonary disease
}

\author{
SEIKO SOEDA ${ }^{1}$, JUNKO H. OHYASHIKI ${ }^{2}$, KAZUSHIGE OHTSUKI ${ }^{2}$, TOMOHIRO UMEZU ${ }^{3}$, \\ YASUHIRO SETOGUCHI $^{1}$ and KAZUMA OHYASHIKI ${ }^{3,4}$ \\ ${ }^{1}$ Division of Respiratory Medicine, Tokyo Medical University; ${ }^{2}$ Institute of Medical Science, Tokyo Medical \\ University; Departments of ${ }^{3}$ Molecular Science, ${ }^{4}$ Hematology, Tokyo Medical University, Tokyo, Japan
}

Received October 18, 2012; Accepted December 17, 2012

DOI: $10.3892 / \mathrm{ijmm} .2013 .1251$

\begin{abstract}
Chronic obstructive pulmonary disease (COPD) is characterized by both chronic inflammation in the airway and systemic inflammation; however, the molecular mechanism of COPD has not been fully elucidated. By measuring microRNA (miRNA) expression in the plasma of COPD subjects, we aimed to identify the clinical relevance of plasma miRNA levels in these patients. Blood samples were obtained from COPD patients and age-matched normal controls. We initially produced plasma miRNA expression profiles using TaqMan low-density array screening. For further validation, individual qRT-PCRs were performed in 40 COPD patients and 20 healthy subjects. TaqMan low-density array screening showed that 9 miRNAs (miR-29b, miR-483-5p, miR-152, miR-629, miR-26b, miR-101, miR-106b, miR-532-5p and miR-133b) were significantly downregulated in the plasma from COPD patients when compared with normal smokers. Among these miRNAs, we focused on miR-106b. A reduction in the plasma miR-106b levels was evident in COPD ex-smokers and COPD current smokers compared with levels in smokers. There was a negative correlation between the plasma miR-106b level and the duration of disease since diagnosis in COPD ex-smokers and the duration of smoking in COPD current smokers. These findings support the concept that progressive reduction in the plasma miR-106b level may reflect persistent and systemic changes even after the discontinuation of smoking in COPD patients. miR-106b may therefore play an important role in the pathogenesis of COPD.
\end{abstract}

\section{Introduction}

Chronic obstructive pulmonary disease (COPD) is a chronic inflammatory disease characterized by persistent airflow limi-

Correspondence to: Dr Seiko Soeda, Division of Respiratory Medicine, Tokyo Medical University, 6-7-1 Nishishinjuku, Shinjuku-ku, Tokyo 160-0023, Japan

E-mail: skume@tokyo-med.ac.jp

Key words: plasma, microRNA, miR-106b, chronic obstructive pulmonary disease, smoking tation, as well as extrapulmonary dysfunction such as skeletal muscle dysfunction, increased risk of cardiovascular disease, osteoporosis and depression (1,2). Diagnosis and assessment of the severity of COPD are based on the degree of airflow limitation by spirometry. However, the forced expiratory volume in $1 \mathrm{sec}\left(\mathrm{FEV}_{1}\right)$ does not directly reflect systemic manifestations in patients with COPD (3). Although both chronic inflammation in the airway and systemic inflammation have been attributed to the pathogenesis of COPD, the origin of systemic inflammation in COPD is not well understood (4-6).

microRNAs (miRNAs) are small noncoding RNAs, ranging from 18 to 25 nucleotides in length, that posttranscriptionally regulate gene expression. Recent studies have shown that miRNAs control a wide range of biological functions such as cellular proliferation, differentiation and apoptosis $(7,8)$. Dysregulation of miRNAs has been implicated in the pathogenesis of several diseases, and their expression patterns in tumor tissues and body fluid serve as biomarkers (9-11). Several studies have examined the role of miRNAs in lung tissue of COPD patients and in airway epithelial cells from smokers versus nonsmokers $(12,13)$. miRNAs exist stably in serum and plasma $(11,14)$, and one recent study revealed the presence of circulating miRNAs within microvesicles (14). Since routine examination using lung epithelium or sputum is sometimes difficult in COPD patients, we sought for altered plasma miRNA expression levels in COPD patients in order to develop a screening protocol for the disease.

In the present study, we profiled levels of plasma miRNAs in COPD patients and identified those that were differentially expressed in COPD. We also assessed clinical characteristics such as smoking history, duration of disease since diagnosis, and the Global Initiative for Obstructive Lung Disease (GOLD) stages of the COPD patients.

\section{Materials and methods}

Patients and samples. A total of 70 consecutive subjects who did not meet any exclusion criteria were invited to participate, and 60 agreed to take part in the study. Participants were classified into 4 groups: those who had never smoked (hereafter 'nonsmokers') without COPD $(n=10)$, current smokers without COPD $(n=10)$, ex-smokers with COPD $(n=20)$, and current smokers with COPD $(n=20)$. Age and gender-matched healthy 
Table I. Characteristics of controls and COPD patients.

\begin{tabular}{lccccr}
\hline & $\begin{array}{c}\text { Non-smoker } \\
\text { without COPD }\end{array}$ & $\begin{array}{c}\text { Smoker } \\
\text { without COPD }\end{array}$ & $\begin{array}{c}\text { COPD } \\
\text { ex-smoker }\end{array}$ & $\begin{array}{c}\text { COPD } \\
\text { current smoker }\end{array}$ & P-value \\
\hline No. of subjects & 10 & 10 & 20 & 20 & \\
Age (years) & $65.0 \pm 11.5$ & $62.8 \pm 14.6$ & $64.6 \pm 7.4$ & $64.7 \pm 7.5$ & 0.95 \\
Male (\%) & 80 & 100 & 85 & 95 & 0.42 \\
Pack-years of smoking & 0 & $47.6 \pm 34.8$ & $69.3 \pm 42.8$ & $77.4 \pm 72.7$ & 0.39 \\
\hline
\end{tabular}

Data are expressed as the means \pm SD (standard deviation). P-values were determined by the ANOVA test. COPD, chronic obstructive pulmonary disease.

subjects were also enrolled in this study (Table I). Current smokers were defined as those who still smoked at the time of participation in the study. Subjects were classified in the COPD group $(n=40)$ if they had a post-bronchodilator ratio of $\mathrm{FEV}_{1}$ to forced vital capacity (FVC) of $<0.70$. All patients with COPD had stable disease; patients with symptoms or clinical signs of COPD exacerbation within 2 months prior to the study were excluded. Other exclusion criteria included a diagnosis of asthma, bronchiectasis, lung cancer, or upper or lower respiratory tract infection in the preceding 4 weeks. Among the 40 COPD patients, there were 21 patients in GOLD stage I, 9 in stage II, 8 in stage III, and 2 in stage IV. This study was approved by our institutional review board (no. 930 , 24 June, 2008), and written informed consent was obtained from all patients prior to collection of specimens, according to the Declaration of Helsinki.

RNA isolation. Isolation of plasma miRNAs for miRNA profiling or quantification of individual miRNAs was performed using the mirVana PARIS kit (Ambion, Austin, TX, USA), diluting $500 \mu \mathrm{l}$ of plasma with $500 \mu \mathrm{l}$ of binding solution. After a 5-min incubation, $1 \mu \mathrm{l}$ of $1 \mathrm{nM}$ ath-miR-159 (Hokkaido System Science, Hokkaido, Japan) was added to each aliquot as a spike control for losses in preparation, and the solution was then vortexed for $30 \mathrm{sec}$ and incubated on ice for $10 \mathrm{~min}$. The subsequent phenol extraction and filter cartridge steps were carried out according to the manufacturer's instructions $(15,16)$.

miRNA expression profile. To assess the levels of specific miRNAs in plasma samples, a fixed volume of $3 \mu \mathrm{l}$ of RNA solution from the 50- $\mu$ l elute was used as input in each reverse transcription (RT) reaction. The RT reaction and pre-amplification step were set up according to the manufacturer's recommendations. miRNAs were reverse transcribed using the Megaplex ${ }^{\mathrm{TM}}$ Primer Pools (Human Pools A v2.1). RT reaction products from the plasma sample were further amplified with Megaplex ${ }^{\mathrm{TM}}$ PreAmp Primers (Primers A v2.1). The expression profile of miRNAs was determined using the Human TaqMan miRNA Array card A (all were from Applied Biosystems, Bedford, MA, USA). This array enables quantification of 377 human miRNAs and 3 endogenous controls (RNU6B, RNU44 and RNU48). Ath-miR-159 was also included as an external reference. qRT-PCR was carried out on an Applied Biosystems 7900HT thermal cycler using the manufacturer's recommended program (GeneSifter; VizX Labs, Seattle, WA, USA).
Quantification of individual miRNAs. To confirm the results obtained from the TaqMan miRNA arrays, we measured expression levels by TaqMan miRNA assays (hsa-miR-106b; 000442; Applied Biosystems). The input of each RT reaction consisted of $10 \mathrm{ng}$ of the total RNA. Using SDS2.2 software (Applied Biosystems), plasma samples were run in duplicates $(15,16)$. Since we could not detect RNU6B in plasma, which is commonly used as an internal standard for miRNA expression analysis in cells, the plasma miRNA expression was calculated based on the $\mathrm{Ct}$ values normalized by those of ath-miR-159, which was spiked in each qRT-PCR aliquot.

Transforming growth factor- $\beta_{1}\left(T G F-\beta_{1}\right)$ measurement. Plasma collected from the 40 COPD patients (20 ex-smokers and 20 current smokers) and 20 healthy controls (10 nonsmokers and 10 current smokers) was used for the measurement of TGF- $\beta_{1}$. The biologically active TGF- $\beta_{1}$ concentration was determined using a commercially available ELISA kit (R\&D Systems, Inc., Minneapolis, MN, USA).

Statistical analysis. GraphPad 5.0 software (GraphPad Software, Inc., San Diego, CA, USA) was used for statistical analysis. The Mann-Whitney test was used to determine statistical significance between 2 groups, and one-way analysis of variance was used to compare 3 or more groups. A P-value of $<0.05$ was considered to indicate a statistically significant difference. The receiver operating characteristic (ROC) curve and the area under the ROC curve (AUC) were used to assess the feasibility of using plasma miR-106b levels for the diagnosis of COPD. We used the Youden index for identification of the optimal cut-off point.

\section{Results}

COPD patient characteristics. There were no significant differences in age, body mass index (BMI), $\mathrm{FEV}_{1}$ (\% predicted), $\mathrm{FEV}_{1} / \mathrm{FVC}$, duration of smoking and pack-years between COPD patients who were ex-smokers or current smokers. The duration of disease since diagnosis in ex-smokers with COPD was significantly longer than that in current smokers with COPD (Table II).

Identification of differentially expressed plasma miRNAs in COPD patients and healthy controls. We first compared miRNA expression levels in plasma obtained from 3 randomly 
Table II. Characteristics of COPD patients.

\begin{tabular}{|c|c|c|c|}
\hline & \multicolumn{2}{|c|}{ COPD } & \multirow[b]{2}{*}{ P-value } \\
\hline & Ex-smoker & Current smoker & \\
\hline No. of patients & 20 & 20 & \\
\hline BMI & $22.2 \pm 3.5$ & $22.5 \pm 3.6$ & 0.76 \\
\hline $\mathrm{FEV}_{1} / \mathrm{FVC}(\%)$ & $52.8 \pm 14.2$ & $58.8 \pm 10.6$ & 0.14 \\
\hline $\mathrm{FEV}_{1}(\%$ of predicted $)$ & $71.5 \pm 25.4$ & $79.7 \pm 24.1$ & 0.30 \\
\hline \multicolumn{4}{|l|}{ GOLD stages } \\
\hline Stage I (n) & 9 & 12 & 0.40 \\
\hline Stage II (n) & 5 & 4 & \\
\hline Stage III (n) & 5 & 3 & \\
\hline Stage IV (n) & 1 & 1 & \\
\hline Duration of smoking (years) & $37.50 \pm 7.78$ & $41.95 \pm 6.24$ & 0.053 \\
\hline Duration of smoking cessation (months) & $59.64 \pm 52.17$ & 0 & \\
\hline Duration of disease since diagnosis (months) & $36.80 \pm 25.60$ & $25.60 \pm 27.29$ & $0.028^{\mathrm{a}}$ \\
\hline Inhaled corticosteroid use, yes/no & $3 / 17$ & $1 / 19$ & 0.61 \\
\hline No. of peripheral neutrophils $(/ \mu 1)$ & $3761 \pm 1322$ & $3987 \pm 1232$ & 0.58 \\
\hline Plasma TGF- $\beta_{1}$ level (ng/ml) & $36.44 \pm 6.53$ & $35.58 \pm 9.23$ & 0.74 \\
\hline
\end{tabular}

Data are expressed as means \pm standard deviation. P-values were determined by the Mann-Whitney test, Fisher exact test, or Chi-square test. ${ }^{\mathrm{a}} \mathrm{P}<0.05$. BMI, body mass index. COPD, chronic obstructive pulmonary disease; $\mathrm{FEV}_{1}$, forced expiratory volume in $1 \mathrm{sec}$. FVC, forced vital capacity; GOLD, Global Initiative for Obstructive Lung Disease; TGF- $\beta_{1}$, transforming growth factor- $\beta_{1}$.

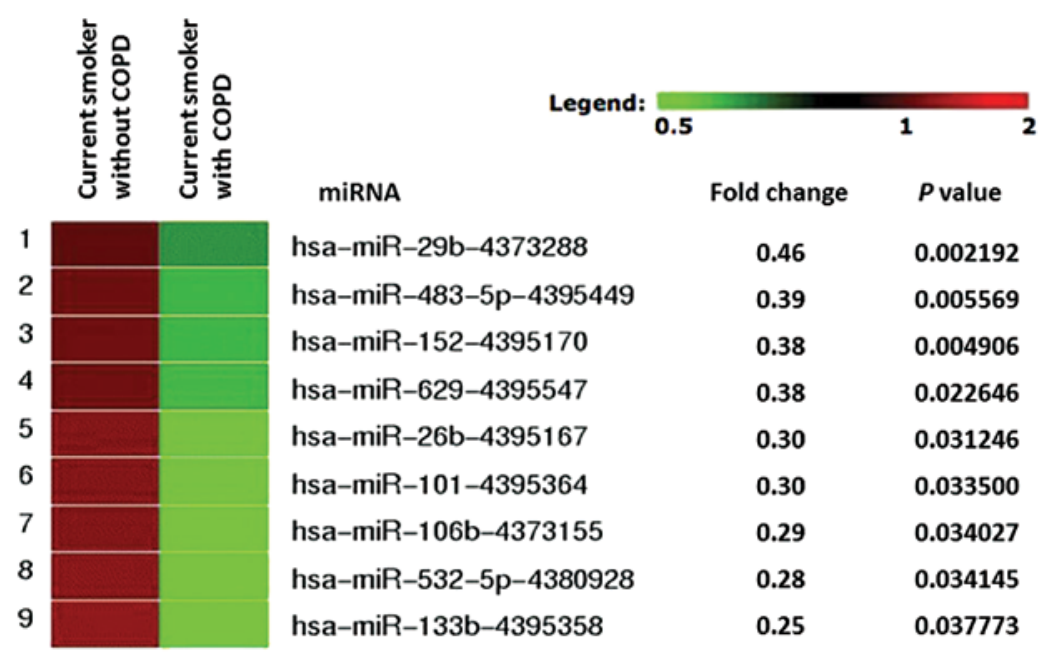

Figure 1. TaqMan low-density array screening of differentially expressed microRNAs in plasma. We compared miRNA expression levels in plasma from current smokers without COPD $(n=3)$ with those from current smokers with COPD $(n=3)$. Nine miRNAs (miR-29b, miR-483-5p, miR-152, miR-629, miR-26b, miR-101, miR-106b, miR-532-5p and miR-133b) were significantly downregulated in plasma from COPD patients.

selected nonsmokers and 3 randomly selected current smokers without COPD. Using the TaqMan low-density array, we found that 6 miRNAs (miR-499-5p, miR-486-5p, miR-19a, miR-92a, miR486-3p and miR-133b) appeared to be downregulated in current smokers without COPD. However, the fold decrease was not significant; those miRNAs were downregulated $<1.5$ fold (data not shown). We next compared miRNA expression in plasma from randomly chosen current smokers without
COPD $(n=3)$ with that of current smokers with COPD $(n=3)$. According to TaqMan low-density array screening (card A), 214 of the 381 miRNAs were expressed in all plasma samples. Of these, 205 miRNAs showed no particular difference in expression level between these 2 groups. Although we did not find any miRNA that was preferentially upregulated in COPD samples, we did find 9 miRNAs (miR-29b, miR-483-5p, miR-152, miR-629, miR-26b, miR-101, miR-106b, miR-532-5p 


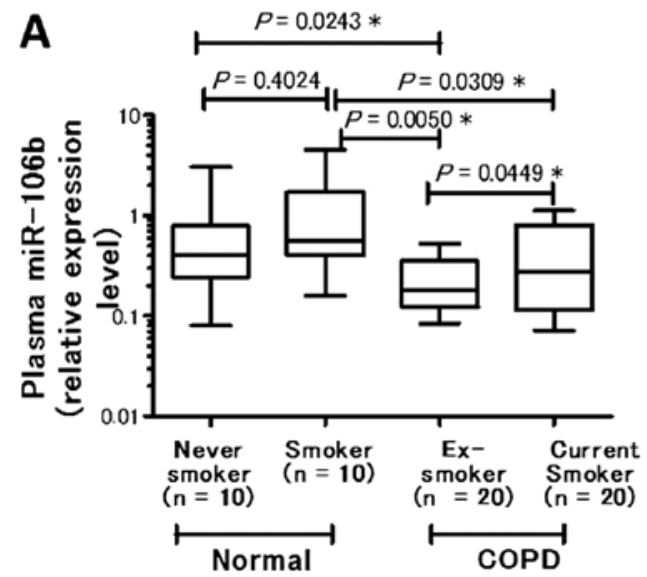

B Normal smoker vs COPD : ROC curve

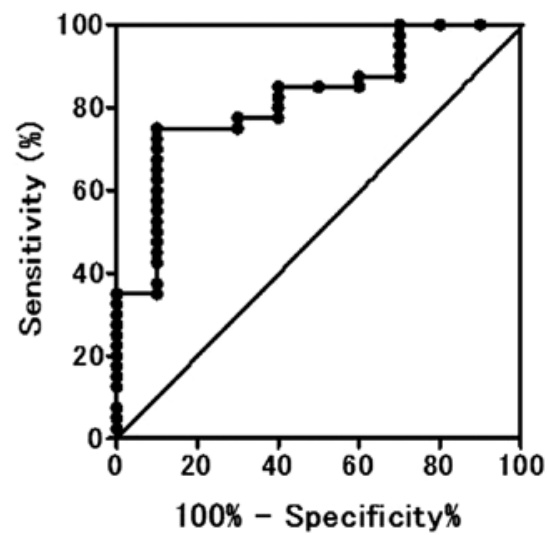

Figure 2. Expression of plasma miR-106b levels in patients with COPD and controls. (A) Expression of miR-106b was determined by qRT-PCR. The plasma miR-106b level in ex-smokers with COPD was significantly downregulated compared with that in current smokers without COPD (P=0.0050). The plasma miR-106b level in current smokers with COPD was significantly lower than that in current smokers without COPD (P=0.0309). Among the COPD subjects, the level of miR-106b in ex-smokers was significantly lower than that in current smokers $(\mathrm{P}=0.0449)$. (B) The receiver operating characteristic curve showed that the cut-off level of plasma miR-106b in all COPD patients at diagnosis was 0.4005 ; the sensitivity was $75.00 \%$ (95\% CI, 58.80-87.31) and the specificity was $90.00 \%$ (95\% CI, 55.50-99.75).

and miR-133b) that were significantly downregulated in plasma from COPD patients, with a fold change threshold of 2.0 or more, using GeneSifter software (Fig. 1).

Plasma miR-106b levels are significantly downregulated in patients with COPD. Based on array fold change, P-value, and the biological relevance of the predicted target by database, such as TargetScan (Table III), the TGF- $\beta$ receptor was thought to be a possible predictive target for miR-106b; therefore, we chose miR-106b for further analysis. Moreover, the level of plasma miR-106b in COPD patients $(n=40)$ was found to be significantly lower than that in normal controls $(\mathrm{n}=20 ; \mathrm{P}=0.00243)$ (data not shown). Among the control subjects, no significant difference in plasma miR-106b level was evident between nonsmokers and smokers $(\mathrm{P}=0.4024)$. The plasma miR-106b level was significantly downregulated in COPD ex-smokers $(\mathrm{P}=0.0050)$ and in COPD current smokers $(\mathrm{P}=0.0309)$ compared with the smokers without COPD. Among the COPD patients, COPD ex-smokers had a significantly lower plasma miR-106b level than COPD current smokers ( $\mathrm{P}=0.0449)$ (Fig. 2A). Based on the results obtained from individual qRT-PCRs of miR-106b, we performed further statistical analysis while combining the data of nonsmokers and current smokers without COPD as controls.

Receiver operating characteristic curve. A receiver operating characteristic curve was generated using the relative expression level compared with normal smoker subjects. The AUC was 0.8200 , indicating $75.00 \%$ sensitivity (95\% CI, 58.80-87.31) and $90.00 \%$ specificity (95\% CI, 55.50-99.75) when the cut-off level of plasma miR-106b in COPD patients at diagnosis was 0.4005 (Fig. 2B).

There were significant differences in age and duration of smoking between COPD patients with plasma miR-106b $<0.4005$ (cut-off level) and those with plasma miR-106b $>0.4005$ (Table IV). COPD patients with plasma miR-106b $<0.4005$ were older $(66.3 \pm 6.0$ vs. $59.7 \pm 9.2$ years;
Table III. Predicted targest for miR-106b.

$\begin{array}{ll}\text { Ankyrin repeat domain } & \text { ANKRD } \\ \text { Bone morphogenetic protein receptor, type 2 } & \text { BMPR2 } \\ \text { Fibrinogen-like 2 } & \text { FGL2 } \\ \text { Integrin } \beta 8 & \text { ITGB8 } \\ \text { Protocadherin 1-protocadherin 13 } & \text { PCDHA1-13 } \\ \text { Transforming growth factor, } \beta \text { receptor 2 } & \text { TGFBR2 }\end{array}$

$\mathrm{P}=0.0121)$ and had smoked for a longer duration (41.2 \pm 7.2 vs. $35.2 \pm 6.0$ years; $\mathrm{P}=0.0219$ ).

Inverse correlations between plasma miR-106b levels and duration of disease since diagnosis and duration of smoking. The plasma miR-106b level was inversely correlated with duration of disease since diagnosis in ex-smokers with COPD ( $r=-0.4611, P=0.0407$; Fig. 3A), although there was no relationship between the plasma miR-106b level and duration of smoking or duration of smoking cessation in COPD ex-smokers (Table V). The plasma miR-106b level in COPD current smokers was inversely correlated with duration of smoking ( $\mathrm{r}=-0.5391, \mathrm{P}=0.0142$; Fig. 3B), while there was no relationship between the plasma miR-106b level and duration of disease since diagnosis in COPD current smokers. Plasma miR-106b levels showed no relationship with $\mathrm{FEV}_{1}$ (\% of predicted), $\mathrm{FEV}_{1} / \mathrm{FVC}$, or GOLD classification in patients with COPD, suggesting that no relationship existed between plasma miR-106b and the severity of airflow limitation (Table V).

Plasma miR-106b and plasma TGF- $\beta_{1}$. The plasma TGF- $\beta_{1}$ level was not significantly elevated in COPD patients compared with healthy controls. However, the plasma TGF- $\beta_{1}$ level was inversely correlated with duration of smoking cessation in ex-smokers with COPD ( $r=-0.5019, \mathrm{P}=0.0241)$ and with $\mathrm{FEV}_{1}$ (\% of predicted) in current smokers with COPD $(r=-0.6333$, 
Table IV. Background characteristics of patients with COPD when subgrouped according to the miR-106b cut-off level.

\begin{tabular}{|c|c|c|c|}
\hline & Plasma miR-106b $<0.4005$ & Plasma miR-106b >0.4005 & P-value \\
\hline No. of patients & 30 & 10 & \\
\hline Age (years) & $66.3 \pm 5.99$ & $59.7 \pm 9.23$ & $0.0121^{\mathrm{a}}$ \\
\hline BMI & $22.0 \pm 3.25$ & $23.4 \pm 4.35$ & 0.298 \\
\hline Pack-years of smoking & $76.3 \pm 63.9$ & $64.6 \pm 42.6$ & 0.595 \\
\hline $\mathrm{FEV}_{1} / \mathrm{FVC}(\%)$ & $54.8 \pm 14.0$ & $58.6 \pm 7.62$ & 0.421 \\
\hline $\mathrm{FEV}_{1}(\%$ of predicted $)$ & $74.5 \pm 26.3$ & $78.9 \pm 20.5$ & 0.635 \\
\hline Duration of smoking (years) & $41.2 \pm 7.16$ & $35.2 \pm 6.03$ & $0.0219^{\mathrm{a}}$ \\
\hline Duration of smoking cessation (months) & $36.6 \pm 52.2$ & $9.60 \pm 17.7$ & 0.120 \\
\hline Duration of disease since diagnosis (months) & $30.7 \pm 27.9$ & $17.20 \pm 26.2$ & 0.186 \\
\hline No. of peripheral neutrophils $(/ \mu 1)$ & $3866 \pm 1172$ & $3884 \pm 1582$ & 0.969 \\
\hline Plasma TGF- $\beta_{1}$ level (ng/ml) & $35.7 \pm 8.19$ & $37.0 \pm 7.29$ & 0.660 \\
\hline
\end{tabular}

Data are expressed as means \pm standard deviation. COPD, chronic obstructive pulmonary disease; BMI, body mass index; FEV $_{1}$, forced expiratory volume in $1 \mathrm{sec}$; FVC, forced vital capacity; TGF- $\beta_{1}$, transforming growth factor- $\beta_{1}$. P-values were determined by the Mann-Whitney test. ${ }^{a} \mathrm{P}<0.05$.
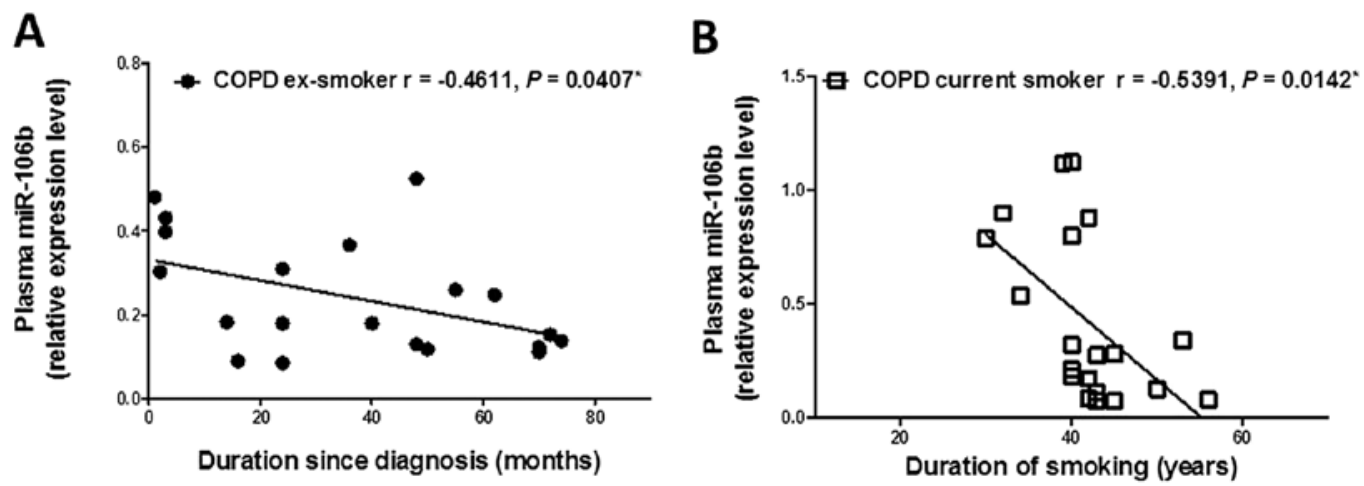

Figure 3. Relationship of plasma miR-106b expression in COPD patients and smoking history. (A) Correlation between the levels of plasma miR-106b and duration of disease since diagnosis in ex-smokers with COPD. Pearson's correlation coefficient (r) is provided. (B) Correlation between the levels of plasma miR-106b and duration of smoking in current smokers with COPD.

Table V. Pearson correlation of miR-106b and clinical characteristics in patients with COPD.

\begin{tabular}{|c|c|c|c|c|}
\hline & \multicolumn{4}{|c|}{ COPD } \\
\hline & \multicolumn{2}{|c|}{ Ex-smoker } & \multicolumn{2}{|c|}{ Current smoker } \\
\hline & Pearson $r$ & P-value & Pearson $r$ & P-value \\
\hline Age (years) & -0.4031 & 0.0781 & -0.2845 & 0.2241 \\
\hline BMI & 0.1359 & 0.5679 & -0.0716 & 0.7643 \\
\hline Pack-years of smoking & -0.0262 & 0.9126 & -0.1772 & 0.4547 \\
\hline $\mathrm{FEV}_{1} / \mathrm{FVC}(\%)$ & 0.2260 & 0.3379 & 0.0842 & 0.7241 \\
\hline $\mathrm{FEV}_{1}(\%$ of predicted $)$ & 0.1009 & 0.6721 & -0.0911 & 0.7025 \\
\hline Duration of smoking (years) & -0.3147 & 0.1766 & -0.5391 & $0.0142^{\mathrm{a}}$ \\
\hline Duration of smoking cessation (months) & -0.2133 & 0.3665 & - & - \\
\hline Duration of disease since diagnosis (months) & -0.4611 & $0.0407^{\mathrm{a}}$ & 0.0911 & 0.7026 \\
\hline No. of peripheral neutrophils $(/ \mu 1)$ & -0.3182 & 0.1716 & 0.3157 & 0.1879 \\
\hline Plasma TGF- $\beta_{1}$ level (ng/ml) & 0.2794 & 0.2329 & -0.0423 & 0.8595 \\
\hline
\end{tabular}

COPD, chronic obstructive pulmonary disease; BMI, body mass index; $\mathrm{FEV}_{1}$, forced expiratory volume in 1 sec; $\mathrm{FVC}$, forced vital capacity; TGF- $\beta_{1}$, transforming growth factor- $\beta_{1}$. ${ }^{\text {P }}<0.05$. 
Table VI. Pearson correlation of TGF- $\beta 1$ and clinical characteristics in patients with COPD.

\begin{tabular}{|c|c|c|c|c|}
\hline & \multicolumn{4}{|c|}{ COPD } \\
\hline & \multicolumn{2}{|c|}{ Ex-smoker } & \multicolumn{2}{|c|}{ Current smoker } \\
\hline & Pearson $r$ & P-value & Pearson $r$ & P-value \\
\hline Age (years) & -0.3781 & 0.1003 & -0.1938 & 0.4128 \\
\hline BMI & 0.3943 & 0.0854 & 0.1399 & 0.5562 \\
\hline Pack-years of smoking & 0.2225 & 0.3458 & 0.2640 & 0.2606 \\
\hline $\mathrm{FEV}_{1} / \mathrm{FVC}(\%)$ & 0.0674 & 0.7778 & -0.3686 & 0.1098 \\
\hline $\mathrm{FEV}_{1}(\%$ of predicted $)$ & -0.0469 & 0.8444 & -0.6333 & $0.0027^{\mathrm{a}}$ \\
\hline Duration of smoking (years) & -0.2431 & 0.3018 & 0.0468 & 0.8447 \\
\hline Duration of smoking cessation (months) & -0.5019 & $0.0241^{\mathrm{a}}$ & - & - \\
\hline Duration of disease since diagnosis (months) & -0.1316 & 0.5803 & -0.2445 & 0.2988 \\
\hline No. of peripheral neutrophils $(/ \mu \mathrm{l})$ & 0.1447 & 0.5428 & 0.4229 & 0.0712 \\
\hline
\end{tabular}

COPD, chronic obstructive pulmonary disease; BMI, body mass index; $\mathrm{FEV}_{1}$, forced expiratory volume in 1 sec; FVC, forced vital capacity; TGF- $\beta_{1}$, transforming growth factor $-\beta_{1} .{ }^{\mathrm{a}} \mathrm{P}<0.05$.

$\mathrm{P}=0.0027)$. The plasma TGF- $\beta_{1}$ level was not correlated with the plasma miR-106 level or other clinical parameters (Table VI).

\section{Discussion}

To the best of our knowledge, this is the first report to substantiate the clinical relevance of plasma miRNAs in patients with COPD. There is an urgent need to clarify the molecular pathogenesis of COPD to improve our understanding of the heterogeneity of COPD patients and the therapeutic efficacy of various treatments (17-19).

This study focused on plasma miRNAs, samples of which can be easily collected, thereby providing a less invasive systematic assessment. Plasma miRNAs were profiled using TaqMan low-density array screening, and miR-106b was selected as a candidate miRNA. We found that the level of plasma miR-106b in COPD subjects was lower than that in smokers without COPD. Our findings indicate that the plasma miR-106b level is related to duration since diagnosis of COPD and duration of smoking.

In a previous study, airway epithelium was used for miRNA profiling between smokers and nonsmokers (13). miRNA expression in COPD patients was also extensively studied in various samples, including sputum (20), fibroblasts (21), muscle (22) and lung tissue (12). In addition, miRNA profiling of lung tissues has been performed using cigarette smoke-exposed rats and a mouse model of lung fibrosis $(23,24)$. Akbas et al (25) currently reported alteration of serum miRNAs in COPD patients; their results were different from our data, possibly due to the different technology, sample materials and race of patients.

The most significant finding of this study was that the plasma miR-106b levels in the current smoker and ex-smoker COPD groups were decreased significantly compared with that of normal smokers. Furthermore, the miR-106b level in the COPD ex-smokers decreased significantly compared with the level in the COPD current smokers. This clearly indicates that miR-106b was progressively downregulated after discontinuation of smoking. This suggests that this alteration could be linked to a systemic reaction even after the cessation of smoking, which is characteristic of COPD patients $(26,27)$. Although it may be difficult to estimate the exact onset of COPD, the plasma miR-106b level was inversely correlated with duration of disease since diagnosis, but not with smoking history or duration of smoking cessation. These findings suggest a relationship between the progressive reduction in plasma miR-106b levels and the deterioration of the COPD condition, even after the discontinuation of smoking.

In silico analysis by microRNA.org (targets and expression), Targetscan 5.2, and PicTar revealed several predicted targets of miR-106b, including ankyrin repeat domain, bone morphogenetic protein receptor type 2 , fibrinogen-like 2 , integrin $\beta 8$, protocadherins $1-13$ and TGF- $\beta$ receptor 2 (Table III). The crosstalk between integrins and TGF- $\beta_{1}$ signaling has been proposed to induce the differentiation of airway fibroblasts to myofibroblasts, resulting in the thickening of small airways in COPD patients (28). Another study found that the TGF- $\beta_{1}$ level of airway epithelial cells was elevated in COPD patients (29), although there were conflicting findings concerning plasma TGF- $\beta_{1}$ levels in patients with COPD $(30,31)$. Although we did not perform a functional analysis to prove a relationship between miR-106b and target genes, miR$106 \mathrm{~b}$ may be involved in TGF- $\beta_{1}$ signaling, since miR-106b regulates the cyclin-dependent kinase inhibitor p21/CDKN1A, which is downstream of TGF- $\beta_{1}(32,33)$.

In this study, we found a significant improvement in the plasma TGF- $\beta_{1}$ level in relation to the length of the period of smoking cessation in COPD patients. In other words, an elevated TGF- $\beta_{1}$ level was associated with the progressive decline of $\mathrm{FEV}_{1}$ (i.e., airway limitation), and the TGF- $\beta_{1}$ level decreased depending on the duration of smoking cessation. In contrast, the plasma miR-106b level progressively decreased, even after the COPD patients stopped smoking. These observations suggest that the plasma TGF- $\beta_{1}$ level was linked to 
airway limitation due to current smoking, whereas the plasma miR-106b level was linked to the mechanism underlying persistent and systemic changes in COPD patients. Therefore, the plasma miR-106b level could be an important clinical indicator for COPD.

Although the number of patients studied was quite small to draw a definitive conclusion, our findings suggest that progressive reduction in the plasma miR-106b level may reflect persistent and systemic changes even after the discontinuation of smoking in COPD patients. Although the biological implications of molecules regulated by miR-106b need to be clarified in future research, the measurement of the plasma miR-106b level could provide important information concerning COPD patients in clinical practice.

\section{Acknowledgements}

We thank Mrs. C. Kobayashi for her technical assistance. We are grateful to Associate Professor Edward F. Barroga and Professor J. Patrick Barron, chairman of the Department of International Medical Communications of Tokyo Medical University, for their editorial review of this manuscript. This study was supported by the Private University Strategic Research Based Support Project 'Epigenetics Research Project Aimed at General Cancer Cure Using Epigenetic Targets', from the Ministry of Education, Culture, Sports, Science and Technology, Tokyo, Japan.

\section{References}

1. Agusti A and Soriano JB: COPD as a systemic disease. COPD 5 : 133-138, 2008

2. Fabbri LM, Luppi F, Beghe B and Rabe KF: Complex chronic comorbidities of COPD. Eur Respir J 31: 204-212, 2008.

3. Celli BR, Cote CG, Marin JM, et al: The body-mass index, airflow obstruction, dyspnea, and exercise capacity index in chronic obstructive pulmonary disease. N Engl J Med 350: 1005-1012, 2004.

4. Barnes PJ and Celli BR: Systemic manifestations and comorbidities of COPD. Eur Respir J 33: 1165-1185, 2009.

5. Sinden NJ and Stockley RA: Systemic inflammation and comorbidity in COPD: a result of 'overspill' of inflammatory mediators from the lungs? Review of the evidence. Thorax 65: 930-936, 2010

6. Decramer M, Janssens W and Miravitlles M: Chronic obstructive pulmonary disease. Lancet 379: 1341-1351, 2012.

7. Chen HY, Yu SL, Li KC and Yang PC: Biomarkers and transcriptome profiling of lung cancer. Respirology 17: 620-626, 2012.

8. Katoh Y and Katoh M: Hedgehog signaling, epithelial-tomesenchymal transition and miRNA (Review). Int J Mol Med 22: 271-275, 2008.

9. Lee EM, Shin S, Cha HJ, et al: Suberoylanilide hydroxamic acid (SAHA) changes microRNA expression profiles in A549 human non-small cell lung cancer cells. Int J Mol Med 24: 45-50, 2009.

10. Mitchell PS, Parkin RK, Kroh EM, et al: Circulating microRNAs as stable blood-based markers for cancer detection. Proc Nat Acad Sci USA 105: 10513-10518, 2008.

11. Etheridge A, Lee I, Hood L, Galas D and Wang K: Extracellular microRNA: a new source of biomarkers. Mutat Res 717: 85-90, 2011.
12. Ezzie ME, Crawford M, Cho JH, et al: Gene expression networks in COPD: microRNA and mRNA regulation. Thorax 67: 122-131, 2011.

13. Schembri F, Sridhar S, Perdomo C, et al: MicroRNAs as modulators of smoking-induced gene expression changes in human airway epithelium. Proc Natl Acad Sci USA 106: 2319-2324, 2009.

14. Hunter MP, Ismail N, Zhang X, et al: Detection of microRNA expression in human peripheral blood microvesicles. PloS One 3: e3694, 2008.

15. Ohyashiki JH, Umezu T, Kobayashi C, et al: Impact on cell to plasma ratio of miR-92a in patients with acute leukemia: in vivo assessment of cell to plasma ratio of miR-92a. BMC Res Notes 3: 347, 2010

16. Yoshizawa S, Ohyashiki JH, Ohyashiki M, et al: Downregulated plasma miR-92a levels have clinical impact on multiple myeloma and related disorders. Blood Cancer J 2: e53, 2012.

17. Vestbo J and Rennard S: Chronic obstructive pulmonary disease biomarker(s) for disease activity needed urgently. Am J Respir Crit Care Med 182: 863-864, 2010.

18. Han MK: Update in chronic obstructive pulmonary disease in 2010. Am J Respir Crit Care Med 183: 1311-1315, 2011.

19. Sakao $S$ and Tatsumi K: The importance of epigenetics in the development of chronic obstructive pulmonary disease. Respirology 16: 1056-1063, 2011.

20. Pottelberge GR, Mestdagh P, Bracke KR, et al: MicroRNA expression in induced sputum of smokers and patients with chronic obstructive pulmonary disease. Am J Respir Crit Care Med 183: 898-906, 2011.

21. Sato T, Liu X, Nelson A, et al: Reduced miR-146a increases prostaglandin $\mathrm{E}$ in chronic obstructive pulmonary disease fibroblasts. Am J Respir Crit Care Med 182: 1020-1029, 2010.

22. Lewis A, Riddoch-Contreras J,Natanek SA, et al: Downregulation of the serum response factor/miR-1 axis in the quadriceps of patients with COPD. Thorax 67: 26-34, 2012.

23. Izzotti A, Calin GA, Arrigo P, Steele VE, Croce CM and De Flora S: Downregulation of microRNA expression in the lungs of rats exposed to cigarette smoke. FASEB J 23: 806-812, 2012.

24. Cushing L, Kuang PP, Qian J, et al: miR-29 is a major regulator of genes associated with pulmonary fibrosis. Am J Respir Cell Mol Biol 45: 287-294, 2011.

25. Akbas F, Coskunpinar E, Aynaci E, Oltulu YM and Yildiz P: Analysis of serum micro-RNAs as potential biomarker in chronic obstructive pulmonary disease. Exp Lung Res 38: 286-294, 2012.

26. Rutgers SR, Postma DS, ten Hacken NH, et al: Ongoing airway inflammation in patients with COPD who do not currently smoke. Thorax 55: 12-18, 2000.

27. Lapperre TS, Postma DS, Gosman MM, et al: Relation between duration of smoking cessation and bronchial inflammation in COPD. Thorax 61: 115-121, 2006.

28. Margadant $C$ and Sonnenberg A: Integrin-TGF-beta crosstalk in fibrosis, cancer and wound healing. EMBO Rep 11: 97-105, 2010.

29. Takizawa H, Tanaka M, Takami K, et al: Increased expression of transforming growth factor-betal in small airway epithelium from tobacco smokers and patients with chronic obstructive pulmonary disease (COPD). Am J Respir Crit Care Med 163: 1476-1483, 2001.

30. Mak JC, Chan-Yeung MM, Ho SP, et al: Elevated plasma TGF-betal levels in patients with chronic obstructive pulmonary disease. Respir Med 103: 1083-1089, 2009.

31. Gong Y, Fan L, Wan H, et al: Lack of association between the TGF- $\beta(1)$ gene and development of COPD in Asians: a casecontrol study and meta-analysis. Lung 189: 213-223, 2011.

32. Marwick JA, Kirkham P, Gilmour PS, Donaldson K, Mac NW and Rahman I: Cigarette smoke-induced oxidative stress and TGF-beta1 increase p21waf1/cip1 expression in alveolar epithelial cells. Ann NY Acad Sci 973: 278-283, 2002.

33. Ivanovska I, Ball AS, Diaz RL, et al: MicroRNAs in the miR-106b family regulate $\mathrm{p} 21 / \mathrm{CDKN} 1 \mathrm{~A}$ and promote cell cycle progression. Mol Cell Biol 28: 2167-2174, 2008. 